\title{
Las utopias del bienestar general: De la idea de ciudad de Thomas More a Yuval Harari
}

\section{The utopias of general well-being: From the idea of Thomas More city to Yuval Harari}

\section{Ángel Emilio Muñoz Cardona (D)}

Escuela Superior de Administración Pública (ESAP), sede Antioquia-Chocó

angel@esap.gov.co

\section{Helmer Quintero Núñez iD}

Corporación Universitaria Adventista (UNAC), Medellín

helmerquintero@unac.edu.co

\section{Resumen}

El fin último de las utopías es el ideario reflexivo de un mundo mejor; más solidario y menos egoísta. Es la búsqueda incesante de un orden social abierto a la simpatía moral, un lugar donde no prevalece la explotación del hombre por el hombre. El objetivo del presente ensayo de investigación es mostrar cuál es la relación y cuáles son los aportes sociales que subyacen en los planteamientos éticos de Thomas More, Tommaso Campanella, Paul Lafargue, Aldous Huxley y Yuval Noah Harari, en el debate contemporáneo de las administraciones de ciudad. Siguiendo un análisis cronológico, lógicodeductivo, el ensayo concluye que no hay una utopía que sea utópica. Existen nuevos esfuerzos sociales, tal vez utópicos pero no imposibles, que buscan construir una ética pública en el diseño de ciudades del aprendizaje, del conocimiento y de la innovación.

Palabras clave: utopía, ciudades del aprendizaje, ciudades de la innovación, ciudades del conocimiento, sentimientos de simpatía.

\begin{abstract}
The ultimate goal of utopias is the reflexive idea of a better world; more supportive and less selfish. It is the relentless pursuit of a social order open to moral sympathy, a place where the exploitation of man by man does not prevail. The purpose of this research essay is to show what the relationship is and what are the social contributions that underlie the ethical approaches of Thomas More, Tommaso Campanella, Paul Lafargue, Aldous Huxley and Yuval Noah Harari, on the contemporary debate of city administrations. Following an analysis, logical-deductive, the essay concludes that there is no utopia that is utopian, there are new social efforts, maybe utopian but not impossible, that seek to build a public ethic in the design of cities of learning, knowledge and innovation.
\end{abstract}

Keywords: utopia, cities of learning, cities of innovation, cities of knowledge, feelings of sympathy.

Clasificación JEL: B14, B15, B51, B52, I31, J1, R1, Z1

Articulo: Recibido el 13 de enero de 2020 y aprobado el 27 de febrero de 2020

\section{Cómo citar este artículo:}

Muñoz Cardona, Á.E. \& Quintero Núñez H. (2020). Las utopías del bienestar general: De la idea de ciudad de Thomas More a Yuval Harari. Reflexión Política 22(44), pp. 135-145. doi: 10.29375/01240781.3800 


\section{Introducción}

"Las personas definen sus necesidades según las costumbres locales que ellas consideran esenciales para una vida digna y, por tanto, su no satisfacción provoca vergüenza"

Adam Smith (1997)

Los avances de la tecnología han permitido el paso de la sociedad moderna a la sociedad contemporánea. En esta última prima el uso generalizado de las páginas web, a través de las cuales ciudadanos de diferentes partes del mundo se unen para expresar lo que piensan, lo que ha dado pie a la existencia de una sociedad planetaria cada vez más fuerte porque está más unida en la defensa del ser humano (Muñoz Cardona, 2017). La sociedad contemporánea, como producto de los grandes avances de las telecomunicaciones, se resiste a aceptar la existencia de profundas distribuciones sociales inequitativas. Cada vez más empresas, gobiernos, cantantes, artistas de cine, deportistas famosos y movimientos civiles, presionados por los cuestionamientos de los colectivos sociales, asumen comportamientos altruistas de responsabilidad social. Cada vez son más las voces que se unen para crear fundaciones, fondos de ayudas, empresas cooperativas y solidarias. Nuevas formas de riqueza social bajo un mismo interés común, tal como lo afirmó Adam Smith en La teoria de los sentimientos morales:

Por más egoísta que se pueda suponer al hombre, existen evidentemente en su naturaleza algunos principios que le hacen interesarse por la suerte de otros, y hacen que la felicidad de estos le resulte necesaria, aunque no derive de ella nada más que el placer de contemplarla (Smith, 1997a, p. 49).

Los seres humanos, por la naturaleza de los sentimientos de simpatía, son capaces de manifestar apoyo y solidaridad. Deploramos de manera natural los abusos de autoridad, pero aplaudimos la condena ejemplar, porque somos seres grupales que aprenden y defienden la existencia de un orden social que es bueno, y es bueno porque nos conviene a todos. Somos seres cooperativos, sensibles a la injusticia, imaginativos y espontáneos. Pero, también, somos seres competitivos y amantes de la comodidad (Muñoz Cardona, 2017).

Para el expresidente de Uruguay, José Mujica, en el ser humano habitan simultáneamente lo racional y lo sentimental, pero ¿cuál de estas dos naturalezas presentes pesa más? La del homo sensible, incluso, a veces, la del impulso instintivo de lo emocional. ${ }^{1} \mathrm{Al}$ respecto, el biólogo inglés Frans de Waal afirma que "no hay que creer a quienes dicen que, como la naturaleza se basa en la lucha por la vida, así es como tenemos que vivir. Muchos animales sobreviven no eliminándose unos a otros o acaparándolo todo para sí, sino a base de cooperar y compartir" (De Waal, 2011, pp. 21-22). De igual manera, afirma Charles Darwin: "todo animal, cualquiera que sea su naturaleza, si está dotado de instintos sociales bien definidos (...), inevitablemente llegaría a la adquisición del sentido moral o de la conciencia cuando sus facultades intelectuales llegasen o se aproximasen al desarrollo a que aquellas han llegado en el hombre" (citado en Cordón, 1982, p. 101).

Los sentimientos de simpatía, más que los exclusivamente racionales, son el motor para el crecimiento político, social y económico de una nación. Por el uso de los sentimientos de simpatía los seres humanos demandan de aprobación para sus actos, lo que da sentido a la vida en sociedad y al uso del lenguaje (Smith, 1997a). Para los economistas y filósofos morales de la ilustración, Adam Smith y John Stuart Mill, la felicidad está referida a la racionabilidad de la experiencia para alcanzar estados de satisfacción personal con la vida, con uno mismo, con el disfrute de los años en armonía con los otros y con lo otro. Sentimientos que están por encima del gozo momentáneo de las ambiciones fruto de los ingresos

1José, "Pepe" Mujica. Conferencia de plenaria en la Celebración por el natalicio del líder revolucionario Ernesto Che Guevara, "90 veces Che". Argentina, 13 de junio de 2018. Centro de Estudios Latinoamericanos Ernesto Che Guevara CELChe, Municipalidad del Rosario. Vídeo disponible en la dirección web: https://www.youtube.com/watch?v=0hjlL2G5ga8 
económicos altos, del placer de la riqueza o de los bienes materiales. La verdadera felicidad está en el valor moral del reconocimiento, de aceptación, de aprecio y de seguridad que nos brindan los demás (Smith, 1997a).

De acuerdo con los retos de idealización para un orden social presentes durante toda la historia de la humanidad, desde la sociedad antigua, medieval y moderna, podemos preguntarnos: dados los avances del conocimiento, ¿tienen las utopías de la felicidad general futuro de materialización en la sociedad contemporánea? El estudio concluye que sí. Anhelos que desde principios del siglo XXI se conocen dentro del orden internacional como ciudades del conocimiento, del aprendizaje y de la innovación.

Se realiza un análisis lógico-deductivo de los planteamientos cronológicos de las utopías, desde el concepto aristotélico de virtud ciudadana hasta la isla de Utopía o Ciudad del Sol; y desde estos fantásticos lugares hasta el derecho ciudadano de Un mundo feliz, capaz de fortalecer el ocio creativo y de dejar atrás todo aquello que nos atrasa como civilización. En otras palabras, se analiza lo que nos permite pasar De animales a dioses. Comencemos por revisar cada una de las utopías, a nuestro juicio más relevantes, desde los inicios de la edad moderna.

\section{Utopia de la vida comunitaria}

Thomas More publicó el libro de filosofía política titulado Utopía, ${ }^{2}$ allí el autor relata la existencia de una isla con un régimen ideal que la gobierna. En la isla Utopía prima la vida comunitaria y el buen gobierno, es un lugar donde no existe la explotación del hombre por el hombre, tanto económica como clerical (Moro, 1993). Es una ciudad isla donde no existen las primacías de las clases sociales, ni donde el orden jurídico estatal es la expresión de la clase poderosa. Utopía es la expresión de una sociedad de iguales, de igualdad de acceso a la justicia, de normas que cobijan a todos los ciudadanos y los protegen por igual (Muñoz Cardona, 2017, p. 51).

El orden político no es secuestrado por los dirigentes de los partidos políticos, ni tampoco es de castas sociales; por lo tanto, el orden político de gobierno es comunitario, no solo en lo referente a la posesión de los medios de producción sino también en la distribución. En la ciudad isla de la Utopía, todos los utopienses trabajan para todos, ya que es la comunidad la que asegura el bienestar y el logro en el cubrimiento de las necesidades básicas (Muñoz Cardona, 2017, p. 52). El hombre no vale por su abolengo, cualidades físicas o riquezas; el hombre vale por ser exclusivamente humano. De allí que la justicia sea el eje integrador de la sociedad. Para conseguir tan loable fin, cada ciudadano practica la disciplina, el autogobierno y el acatamiento de las leyes, valores que son fundamentales para los logros del bien común. Solo de ese modo la justicia, tanto social como jurídica, brindará seguridad a todos los utopienses y con ella la felicidad que otorga una vida en unidad comunitaria (Moro, 1993).

En la isla de Utopía no existe el dogmatismo religioso como ordenador de los comportamientos comunitarios, existe el Estado benevolente, es decir, que distribuye adecuadamente los ingresos públicos en bien de la mejoría de todos, de allí que todos se sientan parte de él. Utopía es una ciudad donde prima el bienestar de toda la comunidad. Los utopienses solo practican la guerra defensiva y preventiva en casos extremos; es decir, cuando se trata de fundar colonias para aliviar la presión demográfica, asegurarse el suministro de materias primas o liberar a los pueblos oprimidos de malos gobiernos (Moro, 1993).

Utopía, de Thomas More, sirvió al judio alemán Karl Marx (1818-1883) para escribir tres obras claves de finales del siglo XIX: Crítica de la filosofia del derecho de Hegel (1843), Manifiesto del partido comunista (1850) y El capital (1867), obras que fueron fundamento de los movimientos comunistas desde 1917 con la Revolución rusa hasta 1989, con la caída del Muro de Berlín. Es decir, Utopía se materializó en el modo de producción comunista de la antigua Unión de Repúblicas Soviéticas Socialistas (URSS), China, Cuba y en la Alemania Oriental conformada después de la Segunda Guerra Mundial. Si bien el movimiento marxista del siglo XX se distancia del pensamiento político de Marx y de Thomas More, al menos por dos razones fundamentales: primero, por el no logro del desarrollo de las fuerzas productivas que facilitan el paso de la economía de mercado socialista al comunismo; segundo, por la fuerte 
violencia de la dictadura del poder popular central y de las masas de proletariados ejercida sobre la misma población. Sin embargo, el comunismo del siglo XIX sí representa un acercamiento al modelo ideal de Utopía, la obra más representativa de los inicios de la edad moderna.

\section{La utopia de la ciencia con sentimiento}

Tommaso Campanella, en su libro La Ciudad del Sol, plantea la utopía de una sociedad que vive en una isla llamada Taprobana, integrada por seres humanos distintos, gracias a la educación en los valores humanos de amor, al hombre mismo y a la sabiduría. Una educación natural de amor al prójimo como a sí mismo para la búsqueda social del bien común. Los taprobianos, basados en los sentimientos de simpatía, conforman una comunidad en la que los valores del egoísmo no tienen cabida por ser deformadores de la solidaridad y de la tolerancia humana (Campanella, 1995, p. 224). ${ }^{3}$

La ciudad del sol es una ciudad del conocimiento donde a la sabiduría le conciernen las artes liberales y mecánicas, las ciencias y sus magistrados, los doctores y las escuelas, es decir, la investigación en todas las disciplinas del saber universal que sirven a la grandeza de la ciudad (Muñoz Cardona, 2017, p. 53). El sabio Sabiduría enseña usando las paredes de las calles que cruzan y organizan la gran ciudad. De esa manera, la ciudad es como una enciclopedia para la enseñanza de todas las ciencias, es una escuela abierta a los ojos de cada habitante. Es el libro en el que todos aprenden el camino de la ciencia y de la solidaridad para la prosperidad: "El Príncipe de la Sabiduría ha hecho representar en todas las murallas, sobre las galerías, por dentro y por fuera, todas las ciencias" (Campanella, 1995, p. 227).
La sabiduría sin amor al hombre carece de sentido en la ciudad del sol. En ella son necesarias la educación técnica y civil de los hijos; el trabajo útil con sentido social; el arte de la farmacia, la siembra, recolección de legumbres y de frutos; la agricultura, la ganadería, las provisiones alimenticias, el arte culinario y, en fin, todo lo referente al alimento, al vestido y a la unión carnal (Muñoz Cardona, 2017, p. 54). De allí que los taprobianos se asombren de aquellos que se preocupan más del bienestar de los perros y de los caballos, que de su misma especie (Campanella, 1995, p. 230). ${ }^{4}$

La prosperidad de los habitantes de una ciudad radica en el trabajo conjunto, en que todos sus miembros viven para el bien de todos y para sí. No es una sociedad de hombres solitarios sino de unión solidaria. Para los taprobianos no es natural que un ciudadano, conociendo el valor de lo humano, bien por experiencia o por el solo sentido de la simpatía, ame más a un animal que a otro ser de su misma especie. No es posible la justicia en una ciudad donde los ciudadanos tienen diferente valor de aprecio a lo humano (Muñoz Cardona, 2017, p. 54).

Los habitantes de la ciudad de Taprobana sostienen que toda la propiedad nace de tener casa por separado, e hijos y mujer propia, y de aquí nace el amor propio, pues por encumbrar con riquezas o dignidades al hijo o por dejarle bienes en herencia, todos se convierten o en depredadores de los bienes públicos, si no tienen miedo, por ser poderosos, o en avaros, insidiosos e hipócritas, si carecen de poder. Por el contrario, cuando dejan de preocuparse por el amor propio, solo les queda el común (Campanella, 1995, p. 231). ${ }^{5}$

Allí radica la importancia de las ciudades del conocimiento en educar al niño en el uso de la ciencia con sentido al servicio de lo humano.

${ }^{3}$ En La Ciudad del Sol, publicado en 1602, de Tommaso Campanella (1568-1639), el monje franciscano se separa de la moral religiosa o búsqueda egoísta de la salvación por la de la moral compartida o civil de amor al otro, de allí que al ser Hoh un hombre sabio, jamás será un gobernante cruel, malvado o tirano, ya que quien conoce una sola ciencia, no sabe verdaderamente ni esa ciencia ni las demás, porque desconoce sus interrelaciones, y que quien está capacitado en una determinada rama científica, aprendida en los libros, es rudo e incapaz de comprender los sentidos y los sentimientos del otro. Por el contrario, esto no acontece a los ingenios dispuestos, conocedores de toda clase de ciencias y aptos para contemplar la naturaleza misma, que es por necesidad el caso de Hoh.

${ }^{4} \mathrm{La}$ ciudad del Sol es un diálogo poético en lo que los interlocutores llevan por nombres Hospitalario y Genovés, piloto de Colón. Es un intento de unidad cultural de finales del siglo XV, cuando en España se expulsa a moros y judíos. Una época de inicios en la conquista del Nuevo Mundo, de guerras religiosas entre cristianos y musulmanes. A través de La Ciudad del Sol, el monje franciscano intenta fundamentar categóricos morales universales de unidad cultural: griegos, judíos, árabes y cristianos. Intento de unificación de dioses, que le lleva a ser condenado por herejía y alboroto social; 30 años de prisión en condiciones infrahumanas. "Questa dolente vita, peggior di mille morti, tant'anni è sepelita, che al número io mi trovo delle perdute genti... (Esta doliente vida, peor que mil muertes, tantos años hace que está sepultada, que me encuentro entre el número de las gentes perdidas...)"; "Io nacqui a debellar tre mali estremi hummaniti: tirannide, sofismi, ipocrisia... ("Yo nací para combatir tres males extremos de la humanidad: la tiranía, sofismas e hipocresía)". En la misma línea de redacción y pensamiento de libertad moral puede ser catalogada la obra del novelista y poeta libanés Yibrán Jalil Yibrán (1883-1931) en los diálogos del Profeta y Almitra.

${ }^{5}$ Párrafo que servirá al pensamiento de Aldous Huxley para desarrollar su obra Un mundo feliz en 1932, e incluso al economista moral John Stuart Mill en su libro publicado en 1848, Principios de Economía Política, con algunas de sus Aplicaciones a la Filosofía Social (1987), quien argumentaba que el Estado debe gravar fuertemente la riqueza, las herencias, las ganancias extraordinarias y no el consumo ni la producción, porque aumenta la pobreza de las clases bajas y la concentración de la riquezas. 
Esa es la importancia que revisten las escuelas y las instituciones de formación que forman en las ciencias de la riqueza, naturales y exactas. Las ciencias de la ingeniería, las artes mecánicas, la física, la química, la política y la economía tienen razón de ser si sirven, como afirmó Aristóteles en la Ética a Nicómaco (Aristóteles, 1097a), al bien común de la ciudad; de allí la importancia de la ética, la estética, la poesía, casas de la cultura, los museos de arte y fotográficos como el de Anna Frank en Holanda, Memoria y Tolerancia en Ciudad de México, la efigie en el parque principal de Yarumal en conmemoración a las 531 víctimas de los Doce Apóstoles y Casa de la Memoria en Medellín, por citar solo algunas (Muñoz Cardona, 2017, p. 54).

En la ciudad del sol todo joven es educado en la ciencia de la investigación, en el amor al trabajo antes que a la lascivia. En el arte de crear y de fabricar cosas que sirvan a todos los miembros de la comunidad, no en el arte del enriquecimiento a través del engaño o del creerse superior por linaje o riqueza, sino en el arte responsable de servir a todos, de trabajar por el bien de toda la humanidad (Muñoz Cardona, 2017, p. 54). Por lo que afirma Campanella: "Por eso, los habitantes de Taprobana, no consideran faltos de nobleza a los artesanos y a los campesinos, y llamamos nobles o doctores a aquellos, que no aprenden ningún arte, viven en la ociosidad y mantienen en el ocio y en la lascivia a tantos servidores para ruina de la república" (Campanella, 1995, p. 233).

Los líderes sociales que viven de la lascivia, del engaño, de la trama o viven de la apariencia son la ruina de la República. En cambio, el que vive del trabajo que producen sus manos, posee una mayor nobleza, porque deja en manos de muchos el juicio sobre el valor de uso de su producto. Los que viven de la lascivia y del arte de la politiquería necesitan mantener mayor séquito de servidores; por lo que secuestran las fuentes de trabajo, buscando cómo hacerse imprescindibles (Muñoz Cardona, 2017, p. 55). Por el contrario, el hombre que vive del trabajo de sus manos es más sabio y más ciudadano, porque con su producto cubre el hambre. Del arte de la lascivia y de la politiquería crece la pobreza y crece el engaño en la ciudad (Muñoz Cardona, 2017, p. 55).

Dicen también que una gran pobreza convierte a los hombres en viles, astutos, ladrones, insidiosos, apátridas, embusteros, falsos testigos, y las riquezas en insolentes, soberbios, ignorantes, traidores, gentes sin amor, que presumen de aquello que no saben. En cambio, la comunidad les hace a todos ricos y pobres: ricos, porque todo lo tienen y poseen; pobres, porque no se convierten en esclavos de las cosas, sino que todas las cosas les sirven a ellos (Campanella, 1995, p. 247).

En la ciudad del conocimiento toda ciencia de la investigación de escuelas y universidades sirve al bien de todos, de allí que todos sean ricos o sean pobres según avancen sus conocimientos para combatir el mal de las enfermedades, de procurar mejores alimentos y artes para la vida. De esta manera, Campanella ve en la formación de lo estético junto con el saber científico la fuente y razón de ser de toda institución de educación; el principio de toda formación natural (Muñoz Cardona, 2017, p. 56). Un hombre formado así será un guerrero capaz de sentir piedad frente a su adversario; un ser incapaz de empuñar un arma y hacer violencia sin sentido. La educación de los sentidos es el principio de génesis universal de amor al prójimo; un acercamiento a la tolerancia, al respeto mutuo, a los actos benevolentes entre todos los ciudadanos (Campanella, 1995, pp. 263-264).

\section{La utopia del fin de las luchas de clase}

Paul Lafargue, en su ensayo titulado Derecho a la pereza, plantea la utopía del bienestar social propiciada por los usos masivos del gran desarrollo tecnológico, electrónico y de la robótica, lo que es propio de las ciudades de la innovación (Muñoz Cardona, 2017, p. 56). Para el pensador francés Lafargue, el uso de los avances tecnológicos y de la robótica en el hacer diario del hombre le liberarán de la esclavitud del trabajo y le permiten disfrutar de más tiempo de ocio, el cual podrá usar en la acción creativa, en la reflexión, en la contemplación, en la educación de los sentidos, es decir, en el mejoramiento de los sentimientos sociales y de sus relaciones personales (Lafargue, 2011).

Lafargue, en su ensayo, Le droit à la paresse, a diferencia de Marx, comulga con la existencia de una economía de mercado más comunitario, gracias a los avances tecnológicos; visión que no compartía el judío alemán: "Al igual que todo otro desarrollo de la fuerza productiva del trabajo, la máquina debe abaratar las mercancías y reducir la parte de la jornada laboral que el obrero necesita para sí, prolongando, de esta suerte, la 
otra parte de la jornada de trabajo, la que el obrero cede gratuitamente al capitalista. Es un medio para la producción de plusvalía” (Marx, 1981, p. 451).

Lafargue ve en la tecnología el instrumento efectivo de bienestar social, a través de la cual todos los hombres se hacen iguales en sus relaciones sociales (Lafargue, 2011). ${ }^{6}$ Los avances tecnológicos rompen con las luchas de clases sociales al acabar con la concentración de capital. La competencia de la producción tecnológica abarata los costos de producción y hace caer los precios de todos aquellos bienes necesarios para una vida mejor. Los empresarios, buscando vender más, harán de sus adelantos tecnológicos consumos masivos y los gobiernos, buscando mayor aceptación popular, harán de dichos adelantos tecnológicos un derecho social (Muñoz Cardona, 2017, p. 57).

En las ciudades de la innovación, gobierno y empresa hacen que todos los ciudadanos vivan mejor. Son ciudades más competitivas en bienestar social, lo que obliga a aumentar la variedad de inventos a más bajos precios. Todo el orden social facilita el acceso al disfrute de nuevos inventos, tal y como hoy lo contemplan las ciudades de la innovación.

La sociedad contemporánea ve en los avances tecnológicos una sociedad en la que los robots y los androides comienzan hacer el trabajo duro del hombre, liberándolo de jornadas largas y repetitivas; lo que le facilita el uso del tiempo libre para el ocio creativo, es decir, para la formación de los sentidos (Muñoz Cardona, 2017, p. 58). Plantea Lafargue que el hombre que tiene más tiempo de ocio puede dedicarse al cultivo de la inteligencia, al conocimiento, a la contemplación musical y artística, a la discusión pública, a mejorar sus relaciones con los suyos, a los sentimientos. La tecnología libera al hombre de la esclavitud de las largas jornadas de trabajo y le mejora en su dignidad.

La pregunta que abrió la obra de Lafargue a la sociedad contemporánea es: ¿hasta qué punto la tecnología compite con el trabajo del hombre? Los desenvolvimientos sociales a lo largo del siglo $\mathrm{XX}$ sirvieron para mostrar que la tecnología es generadora de nuevas fuentes de trabajo calificado y no calificado; fomentadora de nuevos conocimientos y mejores salarios. La tecnología abrió las puertas a un mundo más diverso, seguro y mejor para vivir a un número creciente de ciudadanos; pero, vamos a aclararlo mejor en la explicación de las siguientes dos utopías.

\section{La utopia del control gubernamental natal}

Aldous Leonard Huxley, escritor satírico, escribe la utopía de Un mundo feliz, ${ }^{7}$ en la cual muestra una ciudad futura gobernada por la alta necesidad de trabajo para suplir las ambiciones del consumo. Un mundo feliz es una utopía ética, ya que implica el rompimiento de los lazos familiares, es la individualidad absoluta. Esta obra inicia con los desarrollos en la biología del ADN. El gobierno de la ciudad es el único responsable de las tasas de natalidad, él maneja las densidades poblacionales a través de la administración genética y volumen de incubación de niños probeta. De esta manera, el gobierno de la ciudad fomenta la libertad sexual como mejor disfrute del tiempo libre (Huxley, 2006).

En Un mundo feliz prima la cultura del desarraigo, al crearse seres humanos desprovistos del sentimiento de propiedad, de las acciones de solidaridad y de paternidad. Es un mundo en el que el gobierno de la ciudad le permite al ser humano controlar la ansiedad y la falta de tiempo para disfrutar todo lo que el placer ofrece a través del consumo de medicamentos contra el estrés, el aburrimiento, la idealización suicida, depresión, la ansiedad, la hiperactividad y la falta de sueño (Muñoz Cardona, 2017, p. 200). Es un mundo de bienestar social en el que el gobierno de la ciudad garantiza la felicidad laboral, ya que no rivaliza con el disfrute, pues todo hombre es programado genéticamente en ser feliz con el trabajo manual o intelectual que realiza. La estabilidad en la tasa demográfica facilita el control de los indicadores macroeconómicos más importantes de: producción, inflación y salarios.

En Un mundo feliz, las personas logran ser felices porque llegan a la utopía de la igualdad, gracias a la homogenización de los gustos y preferencias, ya que estos se reducen solo a alternativas de elección de lo que está In, es decir, de moda. A través de esta novela satírica, Huxley explica la

${ }^{6}$ Paul Lafargue (1842-1911) se casó con Laura Marx. Fue periodista, médico, teórico político y revolucionario. Lafargue no compartía la visión de Karl Marx explicitada en la obra de Proudhon, sobre el uso de la tecnología y la obtención de la plusvalía. Desacuerdos que son claramente expuestos en el ensayo Derecho a la pereza (1880).

${ }^{7}$ Aldous Leonard Huxley (1894-1963) escritor inglés que vivió en medio de padres y hermanos biólogos, Huxley fue ampliamente reconocido por sus escritos poéticos y sus novelas satíricas contra la sociedad moderna y sus clases sociales escribe en 1932 "A brave new world", con motivo del gran Sueño Americano o del gran auge industrial de la economía estadounidense de los años 30s. 
imposibilidad natural de lograr masas enteras de poblaciones felices, ya que la felicidad subjetiva del mundo contemporáneo es imposible de medir en términos de bienestar. Si la igualdad y equidad en el gasto público gubernamental no homogeniza las alternativas de elección de los consumidores para el crecimiento económico, hace un efectivo control a las tasas genéticas poblacionales y de natalidad.

En el prólogo al libro, titulado "Brave new world", el judío alemán Theodor Adorno afirma: "Los hombres no son solo meros compradores de los productos en serie producidos por las grandes multinacionales, sino que parecen incluso producidos por la omnipotencia de estos perdiendo su propia individualidad" (Huxley, 2006, p. X); el consumismo, o más bien el consumo masivo de los productos que mueve el mercado, homogeniza formas de comportamiento de los individuos, de ver e interpretar el mundo. Un mundo de estratificación en el que estar a la moda es tener identidad, contribuir con el beneficio económico ante el bienestar que ofrece el sistema de mercado; a lo que el filósofo continúa afirmando: "la falsa conciencia de los individuos que, sin clara solidaridad, ciegamente atados a las imágenes del poder, se creen identificados con un todo cuya ubicuidad les asfixia" (Huxley, 2006, p. XI).

Ese ser humano, estrella de los supermercados, que se individualiza, perdiendo su carácter de persona social y solidaria, es finalmente un ser trascendido por la tecnología, incapaz de pensar un mundo diferente al construido por el sistema de consumo; es decir, de racionalizar los bienes que consume, de ser autónomo. Es el hombre que se fetichiza a sí mismo y se vuelve muestrario de exhibición andante de todo lo que está en moda. Es un ser absorbido por las apariencias, que pierde toda relación social, todo contacto afectivo con el otro, toda corporeidad de amistad para ser un ciudadano feliz.

El mercado define amigos e intimidades, le inventa nuevas relaciones con el otro y con lo otro; lo vuelve esclavo de los bienes que luce y consume sin parar, como lo expresa el cantautor español Joan Manuel Serrat "me gusta todo de ti, menos tú". ${ }^{8}$ O como lo afirma Theodor Adorno: "Lo único que queda claramente sentado es que se trata de un sistema de ciudad clasista racionalizado a escala planetaria, esto es, que se trata de un capitalismo de Estado planeado y sin lagunas, que a la total colectivización corresponde el dominio total, y que sigue funcionando la economía dineraria y el motivo del beneficio privado" (Huxley, 2006, p. XI).

Sin embargo, la utopía de Un mundo feliz reabrió las puertas al concepto de felicidad general promulgada por la escuela clásica y del utilitarismo contemporáneo, quienes ven en la felicidad intersubjetiva una suerte de mejor manera de administrar la ciudad, es decir, la mejor forma de promover el bien común, de lograr la administración pública con valores.

\section{La utopia de la felicidad social}

El historiador judío Yuval Noah Harari, en tres de sus obras: Sapiens: De animales a dioses (2015), Homo Deus (2018) y 21 lecciones para el siglo XXI (2019), expone las utopías de la infotecnologíay la biotecnología que dan pie a las ciudades del aprendizaje, a ciudades que desde su misma organización social permiten aprender por experiencia. La ciudad y sus ciudadanos a través del uso de los avances tecnológicos y del conocimiento son impulsores de las nuevas agendas locales administrativas.

Lo primero a tener en cuenta, afirma Harari, para la medición de la felicidad social, son los conceptos mismos de felicidad subjetiva y felicidad intersubjetiva. La felicidad subjetiva da a entender la valoración individual que cada consumidor da al disfrute de bienes que demanda, valoración microeconómica que puede cambiar con los estados de ánimo o de riqueza de la persona en concreto, como lo hace el índice de felicidad de Pemberton (Beytía y Calvo, 2011). Afirma Harari, "lo subjetivo es algo que existe en función de la conciencia y creencia de un único individuo y desaparece o cambia si este individuo concreto cambia sus creencias" (2015, p. 136). Por el contrario, la felicidad intersubjetiva da cuenta de las relaciones sociales propias de los estados sociales de derecho, y de la capacidad de asociación que tienen los individuos para la consecución del bien común, como lo afirma el historiador judío: "Lo intersubjetivo es algo que existe en el seno de la red de comunicación que conecta la conciencia subjetiva de muchos individuos" (2015, p. 136). Pero, si bien tanto el orden social como político han sido transformados por los avances de la ciencia: ¿somos realmente más felices? ¿Es realmente el mundo un mejor lugar para vivir? (Harari, 2015, p. 412).

${ }^{8}$ Canción Me gusta todo de ti, de Manuel Serrat. Disponible en https://www.youtube.com/watch?v=MEXwhPND6nM 
La economía ha crecido de forma exponencial, y en la actualidad la humanidad goza del tipo de riqueza que solía ser propia de los cuentos de hadas, la ciencia y la revolución industrial han conferido a la humanidad poderes sobrehumanos y una energía prácticamente ilimitada. El orden social se ha transformado por completo, como lo han hecho la política, la vida cotidiana y la psicología humana (Harari, 2015, p. 412).

Noah Harari, en sus obras, ve una correlación positiva entre capacidades humanas y felicidad, al afirmar que las capacidades humanas de aprendizaje y entendimiento, de diálogo y consenso, facilitan los sentidos morales de la simpatía, así como lo entienden los filósofos morales clásicos de la economía: Smith (1997a), Mill (2002), Bentham y Mill (2003), y más recientemente, Amartya Sen (1997). Los sentidos morales invitan a las comunidades a trabajar unidos en pro de un mismo bien común, de beneficio para todos; los invita a ser solidarios, anteponer el altruismo al egoísmo. Por lo tanto, el concepto de felicidad que se debe impulsar en la conformación de los colectivos sociales de ciudad contemporánea es la felicidad intersubjetiva como producto del utilitarismo o de la búsqueda conjunta por la felicidad urbana, es decir, en la felicidad comunal materializada en el disfrute de bienes comunes.
De los índices más usados para medir el grado de felicidad urbana de los países es el Happy Planet Índex realizado por el New Economics Foundations (NEF). A él se han añadido otros como el Social Progress Index del economista Michael Porter (Betía y Calvo, 1995). Pero aún más recientemente, economistas teóricos del utilitarismo o de la utilidad social, entienden el concepto bienestar de la comunidad como satisfacción de condiciones de vida digna, en otras palabras, lo que llaman felicidad general. Por esta razón, ven en el Índice de Felicidad Nacional (IFN), propuesto por el país de Bhután en comparación con el indicador de crecimiento económico del Producto Interno Bruto, uno de los más completos, como se deja ver en el Informe de la Comisión sobre la Medición del Desarrollo Económico (CMPEPS) (Stiglitz, Sen y Fitoussi, 2015; Cervera, 2012). De igual manera, en Colombia, a partir del 2016 se siguen dos índices: el Îndice de Felicidad Nacional del Departamento Administrativo Nacional (DANE, 2016), y el Índice de Felicidad Intersubjetiva del Municipio de Medellín IFI (Plan de Desarrollo Municipio de Medellín, 2016) (tabla 1).

A diferencia de las cuatro variables que se usan para medir el crecimiento de la producción total de un país (PIB), los índices de felicidad nacional (IFN) usan 16 variables para medir el

Tabla 1. Indicadores internacionales y nacionales de felicidad.

\begin{tabular}{|c|c|c|c|c|c|c|c|c|}
\hline Variables e Indicadores & HPI & SPI & $\mathbf{B P}$ & ICV & BLI & IFN & IFI & DANE \\
\hline 1. Salud con calidad & & $\mathbf{x}$ & $\mathbf{x}$ & $\mathbf{x}$ & $\mathbf{x}$ & $\mathbf{x}$ & $\mathbf{x}$ & \\
\hline 2. Educación con calidad & & $\mathbf{x}$ & $\mathbf{x}$ & $\mathbf{x}$ & $\mathbf{x}$ & $\mathbf{x}$ & $\mathbf{x}$ & \\
\hline 3. Diversidad ambiental & $\mathbf{x}$ & $\mathbf{x}$ & $\mathbf{x}$ & $\mathbf{x}$ & $\mathbf{x}$ & $\mathbf{x}$ & $\mathbf{x}$ & $\mathbf{x}$ \\
\hline 4. Nivel o costo de vida & $\mathbf{x}$ & $\mathbf{x}$ & $\mathbf{x}$ & $\mathbf{x}$ & $\mathbf{x}$ & $\mathbf{x}$ & & $\mathbf{x}$ \\
\hline 5. Gobernanza y transparencia & $\mathbf{x}$ & & $\mathbf{x}$ & & $\mathbf{x}$ & $\mathbf{x}$ & $\mathbf{x}$ & \\
\hline 6. Bienestar de la población & & $\mathbf{x}$ & & & & $\mathbf{x}$ & $\mathbf{x}$ & $\mathbf{x}$ \\
\hline 7. Uso del tiempo libre & & $\mathbf{x}$ & & & & $\mathbf{x}$ & $\mathbf{x}$ & \\
\hline 8. Vitalidad comunitaria, tolerancia e inclusión & & $\mathbf{x}$ & $\mathbf{x}$ & & $\mathbf{x}$ & $\mathbf{x}$ & $\mathbf{x}$ & \\
\hline 9. Cultura & & & & & & $\mathbf{x}$ & $\mathbf{x}$ & \\
\hline 10. Nivel de ingresos & $\mathbf{x}$ & & $\mathbf{x}$ & & $\mathbf{x}$ & & & $\mathbf{x}$ \\
\hline 11. Desempleo y empleo & & $\mathbf{X}$ & $\mathbf{x}$ & & $\mathbf{x}$ & $\mathbf{x}$ & & $\mathbf{x}$ \\
\hline 12. NBI & & $\mathbf{x}$ & $\mathbf{x}$ & $\mathbf{x}$ & $\mathbf{x}$ & & & $\mathbf{x}$ \\
\hline 13. Satisfacción con la vida o proyecto de vida & & $\mathbf{x}$ & & & $\mathbf{x}$ & & $\mathbf{x}$ & \\
\hline 14. Esperanza de vida & $\mathbf{x}$ & & & $\mathbf{x}$ & $\mathbf{x}$ & & & $\mathbf{x}$ \\
\hline 15. Movilidad y seguridad & & & $\mathbf{x}$ & $\mathbf{x}$ & $\mathbf{x}$ & & $\mathbf{x}$ & $\mathbf{x}$ \\
\hline 16. Precio de la propiedad & & & & $\mathbf{x}$ & & & & \\
\hline
\end{tabular}

Fuente: Grupo de investigación Gobierno, Territorio y Cultura, Escuela Superior de Administración Pública (ESAP). Las siglas en el cabezote de la tabla corresponden a los siguientes índices de medición de felicidad: Happy Planet Index (HPI), Social Progress Index (SPI), Bienestar Pluridimensional (BP), Índice de Calidad de Vida (ICV), Better Life Index (BLI), Índice de Felicidad Nacional (IFN) y Índice de Felicidad Integral (IFI) (DANE, 2016). 
crecimiento de bienestar de la población. Cada indice de felicidad hace énfasis en las variables de estudio más representativas. Por ejemplo, el Happy Planet evalúa 5: Diversidad ambiental, Nivel o costo de vida, Gobernanza y transparencia, Nivel de ingresos y Esperanza de vida. El Social Progress evalúa 10 variables: Salud con calidad, Educación con calidad, Diversidad ambiental, Nivel o costo de vida, Bienestar de la población, Uso del tiempo libre, Vitalidad comunitaria, Desempleo y empleo, NBI, Satisfacción con el proyecto de vida. El Índice de Felicidad Intersubjetiva (IFI) evalúa 10 variables: Salud con calidad, Educación con calidad, Diversidad ambiental, Gobernanza y transparencia, Bienestar de la población, Uso del tiempo libre, Vitalidad comunitaria, Cultura, Satisfacción con la vida o Proyecto de vida, Movilidad y seguridad. El Índice de Calidad de Vida (ICV) evalúa 8 variables: Salud con calidad, Educación con calidad, Diversidad ambiental, Nivel o costo de vida, Necesidades básicas insatisfechas, Esperanza de vida, Movilidad y seguridad y precio de la vivienda. Finalmente, el índice de felicidad nacional del DANE evalúa 8 variables: Diversidad ambiental, Nivel o costo de vida, Bienestar de la población, Nivel de ingresos, Desempleo y empleo, NBI, Esperanza de vida, Movilidad y seguridad (tabla 1).

Indicadores de felicidad que buscan la utopía de reemplazar el método del cálculo del Producto Interno Bruto (PIB) como indicador de crecimiento económico de los países por el de Felicidad Nacional (IFN), ya que el PIB mide el crecimiento económico en términos de producción e inversión y no en términos humanos de bienestar de la población. El PIB no mide el bienestar de las poblaciones, la transparencia en el uso de los recursos públicos, la calidad de la educación y de la salud, la conservación de los recursos naturales, la calidad de las aceras peatonales y del tráfico para la movilidad, la esperanza de vida, la importancia social de tener una cultura y tener una identidad. Es decir, mide todo menos aquello que nos hace realmente felices como sociedad.

No es el dinero, ni el poder al menos tener un trabajo, ni los ingresos fruto del trabajo lo que nos hace felices como sociedad, sino el bienestar social del que todos y cada uno podemos disfrutar como civilización, como humanidad. Al respecto, afirma Yuval Harari en 21 lecciones para el siglo XXI (Harari, 2019), que los riesgos de pérdidas laborales son en la sociedad contemporánea más altos de lo que realmente fueron en la sociedad moderna, ya que la inteligencia artificial compite con las capacidades físicas y de conocimiento de los seres humanos. Incluso compiten con la habilidad natural de aprender y predecir patrones de comportamiento de otros seres.

A medida que avanza la biotecnología, la inteligencia artificial es capaz de analizar más rápidamente gestos, miradas, preocupaciones, manifestaciones no normales de sudor, temblor o miedo y, por tanto, brindar mejores predicciones. Capacidad competitiva de los androides que puede ser fuente de inestabilidad futura laboral. Sin embargo, aclara Noah Harari, los colectivos sociales no deben trabajar por la conservación de los puestos laborales sino por el bienestar social de todos los seres humanos, ese es el reto de las ciudades del aprendizaje en el siglo XXI.

De allí la pregunta: Can machines of artificial intelligence really think?, pregunta ética que se le formuló al astrofísico británico Stephen Hawking a través de la cadena de noticias BBC de Londres. A lo que respondió sí. Y ante el miedo social de que la inteligencia artificial acabe superando " $a$ la lenta evolución biológica de la especie humana" y pueda ello significar a mediano plazo "el fin de la humanidad”, se le volvió a preguntar: ¿podrán los ordenadores de inteligencia artificial mejorar la felicidad y el bienestar general de la humanidad? ${ }^{9}$ ¿Qué pasaría socialmente si las máquinas de inteligencia artificial compiten con el conocimiento humano, qué sería del hombre en este nuevo escenario productivo? (Muñoz Cardona, 2017, p. 58).

Para el astrofísico británico, la producción de máquinas de inteligencia artificial puede competir con la seguridad económica y emocional del ser humano si el Estado no establece límite al desarrollo de las capacidades tecnológicas de los androides. Los ordenadores pueden ocuparse de aquellos trabajos repetitivos y peligrosos para el hombre, tales como: asear la casa y control a la delincuencia. Otra cosa muy distinta sería si el androide se le construye con capacidad de conciencia, para aprender por sí mismo, racionalizar y competir con el hombre tanto en rapidez como en

${ }^{9}$ Ver página web del periódico el Mundo: http://www.elmundo.es/tecnologia2014/12/02 
habilidad para el trabajo (Muñoz Cardona, 2017, p. 59). ${ }^{10}$

Para el historiador judío, las máquinas no compiten con el trabajo del hombre, lo complementan. La capacidad racional de la máquina estará sujeta a la sensibilidad del hombre. Es el funcionario quien finalmente da la última palabra. Afirmación que se convierte en el llamado ético más fuerte de la utopía contemporánea de Harari. De allí que la sociedad y los colectivos sociales deben trabajar más por entender todo lo que es humano, por el mejoramiento del bienestar social de la humanidad antes que por la conservación de los puestos de trabajo. Lo primero nos mejora como civilización, lo segundo nos atrasa como ciudad.

Afirmación que en la sociedad contemporánea da pie a las ideas de la economía naranja, la cual funda su riqueza en las capacidades naturales del ser humano: creativo, sentir simpatía y solidario; lo que le permite buscar solución a las necesidades comunes locales. En este sentido, se busca que la tecnología y la infotecnología sean unas aliadas del bienestar comunal y no unas destructoras de bienestar del ser humano.

Está nueva forma de entender la riqueza a partir de las capacidades, fortalece las iniciativas de emprendimiento social o comunal. Ningún ser humano en comunidad, por naturaleza, es incapaz de dar solución a sus necesidades más apremiantes si se le deja en libertad de acción social. Las capacidades de un colectivo humano no dependen exclusivamente de la riqueza monetaria, ni de la formación académica, ni de su clase social.

Depende principalmente de sus capacidades naturales y de sus experiencias de vida como el hombre da solución a sus necesidades más apremiantes, así sea de manera burda o artesanal, lo que en La Riqueza de las Naciones de Adam Smith traduce: "Las personas definen sus necesidades según las costumbres locales que ellas consideran esencial para una vida digna y, por tanto, su no satisfacción provoca vergüenza" (Smith, 1997).

\section{Conclusiones}

Si bien el uso de las máquinas de inteligencia artificial representa un sistema cada vez más frecuentemente usado en las áreas de la salud, transporte, seguridad y educación, no significa, desde los fortalecimientos sociales de una ciudad del aprendizaje, del conocimiento o de la innovación, que ellas acaben con el empleo humano; significa que son instrumentos idóneos para salvaguardar la vida, la dignidad y el bienestar de los seres humanos. Para el fortalecimiento de los sentimientos de la simpatía y de la acción solidaria.

Una cosa es resolver algoritmos o dar solución a problemas complejos de optimización matemática, de arquitectura habitacional, de ganancias o de minimización de costos económicos. Otra muy distinta es dar solución a problemas emocionales propios de todos los seres humanos, sentimientos de simpatía que el androide puede imitar pero no incorporar de manera natural, tales como el amor. Esto último implica el fortalecimiento sensible racional del aprendizaje cultural del sentir humano. De la inteligencia emocional, a partir del acuerdo ciudadano de lo que es bueno socialmente, porque nos fortalece a todos como comunidad. Sentimientos de simpatía que facilitan el entendimiento y nos permiten vivir en sociedad, cualidades naturales del ser humano fundamentales en el devenir de las sociedades contemporáneas.

Son ejemplos de ciudad de la innovación más importante de Colombia, el área metropolitana del Valle de Aburrá, con Cultura Metro, las Tiendas de la Confianza, el Banco del Buen Vecino o Bancuadra, los Parques UVA y los Cedezos, iniciativas de la agenda pública que fomentan la solidaridad entre vecinos, son fuente de nuevas iniciativas empresariales, de emprendimiento en los jóvenes, estimulan el ahorro en transporte eléctrico público y el valor ético de la confianza mutua. ${ }^{11}$

El programa "Universidad Digital" de la Gobernación de Antioquia, en el 2018 se convirtió en el principal avance de educación pública gratuita para la formación profesional del 100\% de los jóvenes bachilleres en todo el territorio.

En el 2019, Medellín y el área metropolitana pasaron a ser una de las 10 ciudades de aprendizaje más importantes del mundo. La comunidad, las familias y sus colectivos sociales han sido las promotoras de la conservación de la

${ }^{10}$ Llaman la atención las películas de cine que plantean la evolución, programación y uso de la conciencia en ordenadores. De las más reconocidas se tienen: El hombre bicentenario, actor principal Robin Williams, director Chris Columbu, 1999; El precio del mañana, actores principales Amanda Seyfried y Justin Timberlake, director Andrew Niccol, 2011; Elysium, actor principal Matt Damon, director Neil Blomkamp, 2013; Her, actor principal Joaquin Phoenix, director Spike Jonze, 2013.

${ }^{11}$ Ver documental ¿Por qué Medellín es ciudad innovadora? Disponible en https://www.youtube.com/watch?v=rYiEqWmDGfk La ciudad ganó en el 2013 el premio mundial de la ciudad más innovadora por encima de 200 países por el Banco Mundial, el City Group y el Instituto de Tierra Urbano. 
Cultura Metro, de la conservación del patrimonio público, de la sanción moral a propios y extraños que intentan romper las reglas de la Cultura Metro. De las iniciativas de Juntas de Acción Comunal que trabajan en el embellecimiento de los barrios en manejo de los acopios de basuras en unidades residenciales y calles de los barrios, mantenimiento y siembras ornamentales en antejardines, mejoramiento de las fachadas y aulas de clases lideradas por las mismas organizaciones sociales barriales. De las organizaciones sociales de personas con movilidad reducida y del adulto mayor por la señalización de aceras peatonales, control de velocidad de motociclistas y respeto de los andenes peatonales en los barrios más pobres de la ciudad. Grupos de artistas reconocidos idearon la estrategia de ofrecer obras teatrales gratuitas en las que los asistentes pagan al salir lo que deseen; programas de inclusión social que buscan educar a través de las artes escénicas en temas de ciudad. Así mismo, durante el 2018 y 2019 se reflexionó en los problemas de familia y de pareja.

\section{Referencias}

Aristóteles. (2018). Ética a Nicómaco (Introducción de José Luís Calvo Martínez). México: Madrid: Alianza.

Bentham, J. \& Mill, S. (2003). The classical utilitarians. United States of America: John Troyer.

Beytía, P. y Calvo, E. (2011). ¿Cómo medir la felicidad? Revista Claves de Política Pública, 4, 1-10. Santiago de Chile: Universidad Diego Portales.

Buitrago, F. y Duque, I. (2013). La economía naranja. Una oportunidad infinita. Colombia: Banco Interamericano de Desarrollo BID, Puntoaparte Bookvertising.

Campanella, T. (1995). La política (Grandes Obras del Pensamiento; Trad. Moisés Gonzáles García). Barcelona: Ediciones Altaya.

Cervera Tort, C. (2012). La eudaimonía en Aristóteles y su posible aplicación en la actualidad. Una reflexión sobre la felicidad a partir de la contraposición de la noción actual del término con el concepto aristotélico de eudaimonía. Trabajo de grado, Licenciatura en Humanidades, Universidad Oberta de Catalunya.

Cordón, F. (1982). La función de la ciencia en la sociedad ( $2^{\mathrm{a}}$ ed.). Barcelona: Anthropos.

DANE. (2016). Primer Diagnóstico de Felicidad para Colombia. Presentación del Director del Departamento Nacional de Planeación, Simón Gaviria Muñoz. Bogotá, Colombia.

De Waal, F. (2011). La edad de la empatía: ¿somos altruis- tas por naturaleza? España: Tusquets Editores.

Harari, Y. N. (2015). Sapiens: De animales a dioses. Breve historia de la humanidad. Colombia: Debate.

Harari, Y. N. (2018). Homo Deus. Breve historia del mañana (16 ${ }^{\mathbf{a}}$ ed.). Colombia: Debate.

Harari, Y. N. (2019). 21 lecciones para el siglo XXI. Colombia: Debate.

Huxley, A. L. (2006). Un mundo feliz (Prólogo de Theodor Adorno). México: Porrúa.

Lafargue, P. (2011). El derecho a la pereza. España: Maia Editores.

Marx, K. (1981). El capital: crítica de la economía política (Tomos I, II y III). Colombia: Fondo de la Cultura Económica.

Mill, J. S. (2002). El Utilitarismo (Introducción, traducción y notas de Esperanza Guisán). Madrid, España: Alianza Editorial.

Mill, J. S. (1987). Principles of Political Economy (2a ed.). London: Longmans.

Moro, T. (1993). Utopía. Barcelona: Altaya.

Muñoz Cardona, Á. E. (2017). Ética de responsabilidad ciudadana (2a ed.). Bogotá: Escuela Superior de Administración Pública.

Muñoz Cardona, Á.E. (2018). La felicidad social: un deber hacia la felicidad intersubjetiva en el Chocó colombiano. Sincelejo-Sucre, Colombia. Revista Búsqueda, 5(20), 88-108.

Plan de Desarrollo Municipio de Medellín. (2016). Medellín cuenta con vos 2016-2019. Índice de felicidad Integral para Medellin IFI. Alcaldia de Medellín: Secretaría de Planeación Municipal.

Sen, A. (1997). Capital humano y capacidad humana (Trad. Clara Ramírez). Cuadernos de Economía, 29, 67-72.

Smith, A. (1997). Investigación sobre la naturaleza y causas de la Riqueza de las Naciones. México: Fondo de la Cultura Económica.

Smith, Adam. (1997a). La teoría de los sentimientos morales (Estudio preliminar de Carlos Rodríguez Braun). Madrid: Alianza Editorial.

Stiglitz, J., Sen, A., y Fitoussi, J. (2015). Informe de la Comisión sobre la Medición del Desarrollo Económico y del Progreso Social. Síntesis y recomendaciones. Francia: CMPEPS.

Vásquez, C. (2014). Una medida del bienestar psicológico: El Pemberton Happiness Index. México, Guadalajara: Foro Internacional de Políticas de Bienestar y Desarrollo. Facultad de Psicología, Universidad Complutense de Madrid. 